\title{
The Contribution of Confectionery to the Global Obesity Epidemic: a Review
}

\author{
Simonetta Ballali ${ }^{1}$, Maria Gabriella Vecchio ${ }^{1}$, Daniele Chiffi ${ }^{2}$, Claudia Elena Gafare ${ }^{3}$, Dario \\ Gregori ${ }^{2, *}$
}

${ }^{1}$ Prochild Onlus, Trieste, Italy

${ }^{2}$ Unit of Biostatistics, Public Health and Epidemiology, Dept. Cardiology, Thoracic and Vascular Sciences, University of Padova, Italy

${ }^{3}$ Department of Nutrition, University of Buenos Aires and Food and Diet Therapy Service, Acute General Hospital Juan A. Fernández, Buenos Aires, Argentina

\begin{abstract}
Obesity has become, nowadays, a global concern affecting both developed and developing countries. Nutrition and physical activity represent the major factors influencing energy balance and subsequently weight status. Deciding toward an appropriate intake of all nutrients is seen as necessary to maintain a wholesome lifestyle: among nutrients, sugar plays a major role and its consumption has long been seen as an issue in public health, due to its possible role in displacing or diluting nutrients in the diet and contributing to the epidemic of obesity.

A research on Pubmed was assessed to evaluate the impact of confectionery consumption, as sugar source, on the daily energy intake. The studies considered in the current paper generally failed to show that confectionery consumption leads necessarily to a shift of energy intake. Anyway, considering that till now, very few works on this topic were conducted, more researches are necessary to demonstrate the effective influence of confectionery on daily energy intake.
\end{abstract}

Keywords: Added sugars, confectionery, consumption, daily energy intake, diet, obesity.

\section{INTRODUCTION}

Nowadays there is a remarkable interest on public health nutrition worldwide. Started as a disease targeted at developed countries, obesity has become a rapidly spreading global plague. In less than 30 years, obesity rates grew up globally, showing no flexion through the years in rich countries, while overwhelmingly rising in developing countries [1]. The so called nutritional transition, a change in life style habits due to the economic growth occurred in poor countries, played a relevant role in the development of noncommunicable diseases (NCDs) [2], which represent the most common causes of morbidity and premature mortality worldwide. Nutrition and physical activity represent the major factors affecting energy balance and subsequently weight status, and requiring to be balanced to guarantee a good health status. Chronic diseases are the results of an insalubrious lifestyle, mainly due to physical inactivity and unhealthy diet [3]. In this perspective, an appropriate intake of micro and macro elements is important to guarantee the nutrients' right intake to maintain a wholesome health status. Each nutrient is in fact needed to keep a good state of health, and for this reason worldwide public health authorities have

*Address correspondence to this author at the Unit of Biostatistics, Epidemiology and Public Health, Department of Cardiology, Thoracic and Vascular Sciences, University of Padova, Via Loredan, 18, 35121 Padova Italy; Tel: +39 049 8275384; Fax: +39 02 700445089;

E-mail: dario.gregori@unipd.it initiated several education and communication campaigns in order to promote a lifestyle matching together regular exercise and proper meals consumption. In 1998UK government, food industry and consumer organizations developed a guide, called "the Guideline dietary amount (GDA)", which aimed at counseling on the total amount of energy and nutrients adequate for a healthy diet, and provided science-based advices to promote health and to reduce risk for major chronic diseases. In this perspective, GDA was meant to enable consumers to make informed choices by identifying guideline levels for key nutrients and calories consumed each day. Sugar consumption has long been an issue in public health, due to its possible role in displacing or diluting nutrients in the diet and contributing to the epidemic of obesity in developed countries [4]. However the effective role of added sugar (AS) on health is controversial. On the one hand, some studies reported that consumption of AS may lead to obesity and may displace other more nutrient-dense foods from the diet [5]; on the contrary, several surveys demonstrated that no consistent associations between intake of total sugars and nutrient adequacy exist $[6,7]$. Overall it is recognized that sugar in the diet that comes from many food sources and includes sugar in all its different forms. However, it is not possible to determine what proportion of food might contain AS compared with naturally occurring sugar [8]. AS with alcohol and solid fats are major sources of "discretionary" calories [9] which are extra calories that remain after all the food group requirements have been met. The amount varies 
depending on one's physical activity, age and gender. When available, discretionary calories could be replaced by consuming additional foods from the basic food groups and/or foods in the recommended food groups that are higher in solid fat and/or that contain added sugar [10], and, according to the $\mathrm{WHO}$, they should provide no more than $10 \%$ of the daily dietary energy [11].

In this perspective, the aim of this review is to understand whether the amount of AS consumed daily through confectionery has an impact on the daily energy intake.

\section{MATERIAL AND METHODS}

A research of studies assessing the influence of sugar on the daily energy intake was performed on Pubmed in December 2012. Articles were identified using the string "confectionery" OR "candy" $O R$ "sweeties" $O R$ "confectioneries" $O R$ "candies" $O R$ "golosinas" $A N D$ "daily" OR "24 h" OR "24 hours" OR "diet quality". Twenty-four hours recall method was used as most appropriate to well classify likely heavy-users and neverusers of candies. No restrictions on time or language were applied. All included abstracts were independently identified by two reviewers and paper selection was independently performed in order to select the articles fulfilling the inclusion criteria. The choice of the term confectionery was driven by the necessity to find a unique word set including the same group of different kinds of sweet snacks without any exception.

\section{RESULTS}

The chosen string resulted in 358 items. After reviewing each abstract, 5 studies were identified as pertinent. The objective of the five studies was to evaluate the effect of confectionery consumption and its contribution to the total energy intake and on diet quality. Among those, only one was a randomized clinical trial (RCT) [12] conducted on overweight and obese premenopausal women aged 25-45. In four of the included studies, data were gleaned from the National Health and Nutrition Examination Survey (NANHES)[13-16]. The survey involved children and adolescents aged 2-18 [13, 16], 8-18 [15] and adults aged 19 and older [14]. For all these studies, 24-hour dietary recalls were used to determine intake of chocolate, sugar candy consumption and snacks. Only in the RCT paper, the ingestion of snacks was evaluated during a reduced-calorie diet. In the latter, Piehowski et al. [12] showed that a daily sweet snack, dark chocolate snack (DCS), or a non-chocolate snack (NCS) included in a reduced-calorie dietary pattern promoted body weight reduction and improved body composition in his sample. In both the DCS and the NCS groups, a decrease of waist and hip circumferences (5.7 and $5.8 \mathrm{~cm}$ vs. 3.5 and $5.4 \mathrm{~cm})$, body weight $(\mathrm{p}<0.001)$, fat mass $(p<0.001$ vs. $p<0.01)$ and body fat percentage $(p<0.001$ vs. $p<0.01$ ) was assessed, while no change in lean mass was demonstrated [12]. The impact of confectionery on total energy intake, risk factors for cardiovascular disease and metabolic syndrome, weight/adiposity parameters and diet quality was assessed in O'Neil and colleagues' survey[14], which showed that candy consumption was not associated with adverse health effects in children, adolescents [13] and adults [14]. Furthermore, any association between candies intake and higher levels of any weight parameter was recorded after the comparison among habitual candy consumers and non-consumers. BMI $(27.7 \pm 0.15$ vs. $28.2 \pm$ $0.12 \mathrm{~kg} / \mathrm{m} 2 ; \mathrm{P}=0.0092)$, waist circumference $(92.3 \pm 0.34$ vs. $96.5 \pm 0.29 \mathrm{~cm} ; \mathrm{P}=0.0051)$, and $\mathrm{C}$-reactive protein $(0.40$ \pm 0.01 vs. $0.43 \pm 0.01 \mathrm{mg} / \mathrm{dL} ; \mathrm{P}=0.0487$ ) levels were lower in candy consumers than non-consumers [14]. Candy consumers were also less likely to be overweight and obese than non-candy consumers [13]. Piernas et al. showed a change in snacking behavior in children from 1977 to 2006, with an increase of consumed snacks and a consequent gain in the snacking calories. The percent of snacking calories rose to $27 \%$ ( 113 calories more per day) in all children $2-18$ years, but the largest increase was found among the children aged 2 to 6 years old, who consumed 182 calories more per day [16]. The contribution of low-nutrient-density (LND) food on micro and macronutrient intake and BMI was assessed in a report of Kant [15] which showed that this group of foods, included sweeteners, candy and dessert, contributed more than $30 \%$ of daily energy intake in children and adolescents aged 8-18. LND consumption determined a shift in the amount of nutrient-dense foods intake, with a reduction of energy from protein and dietary fiber $(p<0.05)$ while the energy from carbohydrates and fats resulted positively related to the intake of LND. The assumption of low-nutrient-density food determines a higher energy intake but lower amount of the 5 major food groups (grain, fruits, vegetables, meat and dairy) $(\mathrm{p}<0.001)$ and most micronutrients [15].

\section{DISCUSSION}

Food intake surveys showed that over the past 2 decades, Americans have increased their total energy intake, although at least part of the increase is probably due to better dietary assessment methods [8]. Diets that are relatively high in sugars are postulated to be associated with various health problems such as tooth decay, hyperactivity, and obesity [17, 18]. An interesting finding of the survey was that very few studies were conducted on the impact of confectionery on daily energy intake. Three of the studies considered did not generally show an association between candy or chocolate consumption and increase of energy intake [12-14]. On the contrary, Kant [15] and Piernas's [16] data reported an increase of energy intake due to the consumption of confectionery and a variation in nutrient intake. The first survey was referred to cross-sectional data and did not allow definitive conclusions about displacement of nutrient dense foods by LND and in the second study, a clear concept of snack was not well-defined. In this perspective, it is not possible to affirm that the consumption of sweeties led necessarily to an unfavorable impact on health. Overall conclusions from the considered papers could not be considered definitive in establishing the actual role of AS on energy intake. As demonstrated in Song's survey [19], consumption of AS was not a predictor of obesity in the American population taken that AS's contribution to total energy intake in children, adolescent and adults resulted not significant [19]. Similarly, Golomb concluded that the consumption of chocolate did not affect BMI, but rather adults who participated at her study that were more frequently consuming chocolate had a lower BMI than those who consumed chocolate less often [20]. 
Sugar-rich foods are usually low in dietary fibers and at least moderately high in energy density, both elements potentially linking high sugar intake with obesity. Likewise previous findings, after reviewing data on the effects of dietary carbohydrates on body fatness, van Dam and Astrup concluded that there was insufficient evidence that an exchange of sugar to non-sugar carbohydrates would assist in body weight reduction [21]. Merchant also considered carbohydrates intake, concluding that low-carbohydrate diet was associated with greater likelihood of being overweight or obese among healthy, free-living adults [22]. Conversely, Bowman demonstrated that people who took more than the $18 \%$ of their total energy intake from AS had the lowest mean intakes of all micronutrients [23], assumption that was afterwards confuted by Rennie that stated that there were insufficient data and several inconsistencies between studies investigating on the relationships between AS and micronutrient intakes, with no clear evidence of micronutrient dilution [24]. An additional insight was given more recently by Forshee who concluded that in children and adolescent, added sugars tended to be associated with lower consumption of vegetables and fruits, and it is associated with an increase of the intake of meat and grain [25].

In this perspective, it is not possible to conclude that the consumption of confectionery necessarily leads to a shift of energy intake. As pointed out in Fogelholm and Tetens' editorial [26], the study of the association between sugar and bodyweight might be an extremely reductionist approach, since carbohydrates are a part of the whole diet, sugars are a part of total carbohydrates and solid sugars a part of total sugars. Sugar coming from candies is eventually part of the solid sugar subgroups, coming therefore at the very end of the considered chain, and as O'Neil concluded, its contribution on total AS was very little [13]. This could be added to the fact that as seen in Kirk,snacking for most individuals appeared not to adversely affect body-weight control, and for some it may improve control, due to the fact that frequent eating helps appetite control [27].

These highly inhomogeneous findings are for instance due to the absence of common definitions. As pointed out from Sigman-Brown and Morita [28], a myriad of terms is currently used to describe these ingredients. In their paper, they concluded that the examination of published data suggested a lack of rigor in regard to sugars' classifications, specifically concerning accuracy of measurements, reported intakes, and estimates of availability. Keeping these concerns in mind, some methodological issues have additionally been considered. The use of epidemiologic studies as the primary basis for current questions regarding the effect of sugars on health, specifically obesity, may generate misleading conclusions. A recent work on the Australian population [29] revealed that although a substantial decline in refined sugars intake was recorded, obesity increased over the same timeframe, implying that the effort to reduce sugar intake may have reduced consumption, without decreasing the prevalence of obesity. A similar work at population level was published on New Zealand data [30], concluding that current sugars or sucrose intake was not associated with body weight status in the New Zealand population.
Lack of definitions and of proper designs, able to give an insight on causality and not only on association, seems to bias current research on AS contribution to daily energy intake. These methodological issues severely limit the possibility to extend these results to population level. A recent work from Vyth and colleagues [31] highlighted the urgent need in nutrition science of longitudinal, randomized, controlled design in a real-life setting.

In this scenario, conflicting results cannot be taken as sound knowledge to implement dietary recommendations for consumers, which have to be addressed with clear message based on evidence based data.

\section{CONFLICT OF INTEREST}

The authors confirm that this article content has no conflicts of interest.

\section{ACKNOWLEDGEMENTS}

This research was partially funded by an unrestricted grant of the University of Padova and of Prochild ONLUS. The work has been partially supported by an unrestricted grant of the Italian Ministry of Foreign Affairs under the program "Programmi di alta rilevanza scientifica e tecnologica Italia-Messico".

\section{REFERENCES}

[1] Lam DW, LeRoith D. The worldwide diabetes epidemic. Curr Opin Endocrinol Diabetes Obes 2012; 19(2): 93-6.

[2] Zarbato Longo G, Das Neves J, Gontijo de Castro T, et al. Prevalence and distribution of risk factors for non-communicable chronic diseases among adults from Lages city, South of Brazil, 2007. Rev Bras Epidemiol 2011; 14(4): 698-708.

[3] WHO. Preventing chronic diseases: a vital investment. Geneva: WHO. World Health Organization, 2005.

[4] Murphy S, Johnson R. The scientific basis of recent US guidance on sugars intake. Am J Clin Nutr 2003; 78: 827-33.

[5] Harnack L, Stang J, Story M. Soft drink consumption among US children and adolescents: nutritional consequences. J Am Diet Assoc 1999; 4: 436-41.

[6] Farris RP, Hyg MS, Nicklas TA, et al. Nutrient intake and food group consumption of 10-year-olds by sugar intake level: The Bogalusa Heart Study. J Am Coll Nutr 1998; 17: 579-85.

[7] Gibney M, Sigman-Grant M, Stanton Jr JL, et al. Consumption of sugars. Am J Clin Nutr 1995; 62: (Suppl): 178S-94S.

[8] Murphy SP, Johnson RK. The scientific basis of recent US guidance on sugars intake. Am J Clin Nutr 2003; 78(4): 827S-33S.

[9] Reedy J, Krebs-Smith SM. Dietary sources of energy, solid fats, and added sugars among children and adolescents in the United States. J Am Diet Assoc 2010; 110(10): 1477-84.

[10] Scidell JC. Epidemiology of obesity. Semin Vasc Med 2005; 5: 314.

[11] Organization WHO. Diet, nutrition and the prevention of chronic diseases: report of a Joint WHO/FAO Expert Consultation. Geneva, Switzerland: World Health Organization 2003.

[12] Piehowski KE, Preston AG, Miller DL, et al. A reduced-calorie dietary pattern including a daily sweet snack promotes body weight reduction and body composition improvements in premenopausal women who are overweight and obese: a pilot study. J Am Diet Assoc 2011;111(8):1198-203.

[13] O'Neil CE, Fulgoni VL III, Nicklas TA. Association of candy consumption with body weight measures, other health risk factors for cardiovascular disease, and diet quality in US children and adolescents: NHANES 1999-2004. Food Nutr Res 2011; 55.

[14] O'Neil CE, Fulgoni VL III, Nicklas TA. Candy consumption was not associated with body weight measures, risk factors for cardiovascular disease, or metabolic syndrome in US adults: NHANES 1999-2004. Food Nutr Res 2011; 31(2): 122-30. 
[15] Kant AK. Reported consumption of low-nutrient-density foods by American children and adolescents: nutritional and health correlates, NHANES III, 1988 to 1994. Arch Pediatr Adolesc Med 2003; 157(8):789-96.

[16] Piernas C, Popkin BM. Trends in snacking among U.S. children. Health Affairs (Millwood) 2010; 29(3): 398-404.

[17] DiBattista D, Shepherd ML. Primary schoolteachers' beliefs and advice to parents concerning sugar consumption and activity in children. Psychol Rep 1993; 72(1): 47-55.

[18] Milich R, Wolraich M, Lindgren S. Sugar and hyperactivity: A critical review of empirical findings. Clin Psychol Rev 1986; 6(6): 493-513.

[19] Song WO, Wang Y, Chung CE, et al. Is obesity development associated with dietary sugar intake in the U.S.? Nutrition 2012; 28: 1137-41.

[20] Golomb BA, Koperski S, White HL. Association Between More Frequent Chocolate Consumption and Lower Body Mass Index. Arch Internal Med 2012; 172(6): 519-21.

[21] van Dam RM, Seidell JC. Carbohydrate intake and obesity. European journal of clinical nutrition 2007; 61 (Suppl 1) :S75-99.

[22] Merchant AT, Vatanparast H, Barlas S, et al. Carbohydrate intake and overweight and obesity among healthy adults. J Am Diet Assoc 2009; 109(7): 1165-72.
[23] Bowman S. Diets of individuals based on energy intakes from added sugars. Fam Econ 1999; 12: 31-8.

[24] Rennie KL, Livingstone MB. Associations between dietary added sugar intake and micronutrient intake: a systematic review. $\mathrm{Br} \mathrm{J}$ Nutr 2007; 97(5): 832-41.

[25] Forshee RA, Storey ML. The role of added sugars in the diet quality of children and adolescents. J Am Coll Nutr 2011; 20(1): $32-43$.

[26] Fogelholm M, Tetens I. Is candy eating a way to control body weight? Food Nutr Res 2011; 55.

[27] Kirk TR. Role of dietary carbohydrate and frequent eating in bodyweight control. Proc Nutr Soc 2000; 59(3): 349-58

[28] Sigman-Grant M, Morita J. Defining and interpreting intakes of sugars. Am J Clin Nutr 2003; 78(4): 815S-26S.

[29] Barclay AW, Brand-Miller J. The Australian paradox: a substantial decline in sugars intake over the same timeframe that overweight and obesity have increased. Nutrients 2011; 3(4): 491-504.

[30] Winsome P, Noela W, Donnell A, et al. Exploring the relationship between sugars and obesity. Public Health Nutr 2008; 11(08): 8606.

[31] Vyth EL, Steenhuis IHM, Brandt HE, et al. Methodological quality of front-of-pack labeling studies: a review plus identification of research challenges. Nutr Rev 2012; 70(12): 709-20.

(C) Ballali et al.; Licensee Bentham Open.

This is an open access article licensed under the terms of the Creative Commons Attribution Non-Commercial License (http://creativecommons.org/licenses/by-nc/3.0/) which permits unrestricted, non-commercial use, distribution and reproduction in any medium, provided the work is properly cited. 